\title{
Social Realities of Higher Education in the Age of Uncertainties
}

\author{
Dr. Smita R. Deshmukh \\ Principal \\ Shri Shivaji Arts and Commerce College \\ Amravati, Maharashtra, India \\ principalsmitadeshmukh@gmail.com
}

\begin{abstract}
Education is an enlightening experience and social process. The new social realities, particularly the interplay between democratization of education emergence of knowledge, society and globalization greatly influence the educational process of all societies. There exists a paradoxical situation of limited higher education opportunities and a large pool of unemployable educated in India. This is partly a result of the failure of our education system to develop the competencies required for the world of work. Such competency to face epidemics of Corona and value education, i.e., sensitivity, the ability and a skill to do job or business, is expected outcome of any good education system. The student should realize that they have the right for quality education as well as quality healthy life and they also have learning responsibilities to enable the institution to provide quality education. The students and staff should mutually reinforce their efforts for quality education. The 21 century is an age of accelerated change, the age of ICT that is Information and Communication Technology. We are happy to welcome 2020 which presents a powerful message that this is an age of Knowledge, age of Quality at the same time we are facing covid 19 corona in this age of Uncertainties. In this scenario, higher education is essential
\end{abstract}


for survival. We are having in an important and epoch-making age. We look at higher education for solutions.

Keywords: Higher Education, Students, Social Realities, Value Education, Corona, Information and Communication Technology, Knowledge Society.

Introduction

Development of the nation depends on all-round and well-balanced personality of the students. With the help of human intellect, our learner can help make our nation more vibrant, with innovation, compassion and passion. Democratic, cohesive, socially responsible, culturally rich and intellectually smart student is need of competitive nation.

Nobel Laureate Amartya Sen considered the education and health as two vital elements for the realization of full potential of individuals and nations. India is known for its rich cultural and spiritual heritage, but like whole world India is fighting against corona and also expecting the need for a value-system through education has been felt and recognized through centuries. Value system play an important role in any decision making process. In fact, every human action is the reflection of personal and social values.

Higher Education in India is passing through tremendous change. India has become third largest system in the World among institutions and students. Since Independence, the country has witnessed extensive progress in the field of higher education. However, there are serious concerns and issues in higher education that need to be addressed in neoliberal era.

When there is a chaos and crisis of epidemics amongst individual, family, institution, state, nation and world then the life of human being should have top priority. We should try our 
heart and soul to bridge the gaps between developed and developing mindset. The liberal art should be strengthened. The culture of India can be revived through powerful cultural heritage. Teacher education policy, health education policy, ICT education policy should have same status as that of Economic and Fiscal policy. Education has to sustain and demonstrate its true identity.

The government is keen to open the higher education sector to the private providers, either through public-private-participation or foreign direct investment in higher education. One section is opposed to commoditization of education; the other section thinks that private sector is the only way out. Moreover, the overall scenario of higher education in India does not match with the global quality standards. Knowledge production is a lengthy and rigorous process. The overall sustainable development of the society depends on the two watchwords of knowledge production namely relevance and utility. Higher education highlighted the crisis in the unemployment, weakening of student motivation, deterioration of standards. Concepts of access, equity, relevance and quality in higher education can be functionalized only if the system is both effective and efficient.

The architecture of Education System varies widely among nations. Knowledge building society in higher education sector is increasing at a very fast pace resulting in increase in competition between universities and institutions with similar missions. The function of university is to provide the higher education and training in relevant field. In India, the quality of higher education has always been under discussion. There may have not been two opinions for continuous assessment and improvement is necessary for improving the quality of Higher Education.

Assessment is one of the key factors of the teaching learning process and our education system is largely dependent upon the teaching learning process. It identifies the lying weakness 
of students in the concerned area. Colleges and universities should increasingly find themselves in an environment that is conducive to understanding the role and importance of congenial environment which encourages new thinking and innovation.

Higher education is identified with research and development, germination, incubation, creation, construction and connection. Indian higher education is being governed by neo-liberalism, new-capitalism, and neo-colonialism. The private sector is replacing public sector. Private colleges and universities are being opened. There is borderless reach for the students of various countries. Earlier the society was governing the society. Now the economy is overarching all the education, society and state. Our society, culture, Education all are being governed by capitalism. The higher education is very high cost, because there is commoditization of higher education. There is in-equation of compensation and performance. Return on investment is measured in terms of money and material rather than humanity, patriotism, integrity. Those who have never to purchase higher education of any kind from anywhere at any time can purchase it. These producers and consumers have liberal, borderless, global markets.

All the qualities can be the parameters to assess the quality of education. The National Assessment and Accreditation Council (NAAC) have indentified core values of higher education institutions as goals of their activities. (1) Contribution to national development, (2) Fostering global competencies among students, (3) Promoting the use of technology, (4) Inculcating value systems in students, (5) Quest of excellence. This framework provides a broad vision of higher education in India. Indian colleges and universities are facing major changes as they navigate the $21^{\text {st }}$ century and make decisions that will contribute competitiveness in the global market. Higher education in India systematically progressing an educational front. UGC enforces its 
standard to coordinate between centre and the state as the main governing body. The assessment is mainly designed to promote quality improvement and institutional accountability. "Wisdom knows what to do next, skill knows how to do it, and virtue, is doing it". This was observed by David Jordan, famous writer and philosopher. We need to live happier, healthier and more fulfilling life.

MHRD Government put forward the planning of NEP to strengthen education which would be one more major step in realizing the vision, mission of Higher Education ensuring that the university sustains highest standards of education and research. He talked of research having several aspects including enrichment of knowledge to provide solutions to several problems of the society. By the appropriate use of Science and Technology, researchers can utilize their talent to plan right strategies for environmental sustainability. This includes areas of energy, water, health, increasing agricultural production, food security along with values.

\section{Is Higher Education changing?}

We observe tremendous change in the industry of education. UGC is making various efforts. The need to establish knowledge-based society brought commendable reforms in Higher Education have initiated change in the education sector to ensure expansion, inclusion and excellence. Educational Institution promotes academic excellence to maximize accountability, transparency, procedural fairness in administration and evaluation. A fully detailed action plan always helps learners by pre-determining the outcome of a course faculty should communicate the performance expectations to the learners and connect the goals to the grades.

Learners should take the responsibility to learn. The teacher is the facilitator and should check the climate of the class that is physical arrangement, conducive environment, text-books, 
etc. It is effective when learner's psychological willingness, collaboration, mental makeup are optimized to the fullest. The preparatory lecture is vital to break the ice with the group and understand its mindset as well as to communicate one's own idea about the subject matter. Teaching and learning should also focus on moral and ethical education with the emphasis on social justice and equity. Value based education is linked to skills paradigm as it supports and encourages the personal growth of an individual. Decision making, positive thinking, stress management, awareness of social evil, social responsibilities, integrity are to be instilled with an intention to holistic person of development.

The essential elements of a quality higher education are: motivated students, committed staff, appropriate teaching, learning, evaluation methods, sufficient infrastructure, and efficient governance system. The graduates are expected to be creative, innovative with social sensitivity and communication skills. They should be willing to take responsibilities and to become entrepreneurial. Graduate citizens of India should be flexible, to be able to cope up with uncertainties. They should prepare themselves for internationalization of the labor through understanding of various cultures and languages.

The quality of nation depends upon the quality of its citizens and particularly on its teachers. Globalization of the economy has thrown up the new challenges before the higher education systems. To produce quality students it is necessary that quality teaching is imparted and development of teacher depends upon many factors. Promotion of research is crucial for excellence. Evaluation of the students and teacher is to assess the overall performance of the teaching learning experience in terms of quantitative and qualitative dimensions.

Indian higher education system is the third largest in the world, next to the United States and China. Since independence, India as a developing nation is contentiously progressing in the 
education field. Although there have been a lot of challenges to higher education system of India but equally have lot of opportunities to overcome these challenges and to make higher education system much better. It needs greater transparency and accountability, the role of colleges and universities in the new millennium, and emerging scientific research on how people learn is of utmost important. India need well-skilled and highly educated people who can drive our economy forward. India provides highly skilled people to other countries therefore; it is very easy for India to transfer our country from a developing nation to a developed nation.

Education is recognized as one of the critical elements of the national development effort. Improvement of access along with equity, excellence, the adoption of state specific strategies, enhancing the relevance of higher education through curriculum reforms, quality in research, IT, networking, distance learning are some main policies of higher education. In the recent Education Policy, emphasis has been laid on the expansion with equity, use of ICT in education, promotion of research and quality education. It is universally proved that education is based on expansion, inclusion and excellence.

Values in the higher education make one's own life and life of fellow beings worthy and meaningful. Value education is a many sided endeavor and in an activity during which young people are assisted by family members, teacher and society value education, is thus concerned to make morality a living concern for students. Hence, what is needed is value-education. Despite many educators and educationists description regarding value-education, it cannot be denied that continuing research will continue to making the description of value- education more adequate.

Knowledge now is treated as commodity. Science in this age is not mere search for truth; it is a search for response to economic, political and social interests. Education and research are transforming the entire social structure, creating a knowledge based society. Skilled labor force 
to utilize that knowledge is the back bone of the national economy. Knowledge is potential power. This can be transformed to actual power only when we act on it. It determines the growth of India as a knowledge superpower is the growth in knowledge economy for learner's empowerment.

The Modern India has committed to the guiding principles of socialism, secularism, democracy, national integration and so on. These guiding principles should be emphasized in the educational system and suitable values; are to be included in the students for promoting equality, social justice, national cohesion and democratic citizenship. With these aims in view, radical reforms in the present lop-sided education are to be introduced and all attempts need to be made for developing well-integrated personalities for our individuals. Hence, there is need for inculcating desirable values

MHRD government of India is taking quality initiatives in with the help of new-age learning tools, swayamprabha, such as DTH programs, educational channels, AIR, Diksha, E-pathashala, NPTEL, ATAL, Shoghganga, Widwan, Swayam, IGNU, opensource softwares are used. In Corona lockdown period, it is easy for a country like India to overcome these problems and bring a paradigm shift in the country's higher education sector. India launched satellite for education in 2004. The virtual labs, thirty two channels are providing education to large population properly. Now knowledge is imparted using advanced digital teaching and learning tools, and society is made aware of where we are not lagging behind, India can easily emerge as one of the most developed nations in the world in the age of uncertainties.

Government is trying to fulfill demand and requirement of higher Education sector. So it is necessary to identify the promising areas for private and foreign investments. Indian education System is fast growing education industry. India made the strategic engagement and capacity 
building in higher education leadership and management at the national and international level on areas of systemic reform, including quality assurance, international credit recognition, and unified national qualifications framework. Education to all and higher education is considered essential because higher education is a powerful tool to build up a nation.

India is in the throes of great developments in the field of higher education. At the same time, it has been widely recognized that the country has a unique opportunity to convert its demographic surplus into its economic strength by providing its young people the right kind of skills. Apart from an analysis of the prevailing situation, anyone will suggest a framework for the creation of a competitive environment in higher education that would ensure better utilization of public funds and improvement of both public and private institutions.

Higher education can be defined as the mother of all professions. Education is a process by which a person's body, mind and character are formed and strengthened. This has not only excluded a large section of the population from contributing to the development of the country fully, but it has also prevented them from utilizing the benefits of whatever development have taken place for the benefit of the people.

\section{Conclusion:}

The higher education shape the behavior, minds, and social and human value of the student community. The demand of higher education has thus increased by leaps and bounds. India is a country of huge human resource potential, to utilize this potential, properly is the issue which needed to discuss. Opportunities are available but how to get benefits from these opportunities and how to make them accessible to others is the matter of concern. The higher 
education policy should be able to enhance knowledge with skills and develop appropriate attitudes so that our human resource becomes more dynamic in promoting the development of nation. We talk a lot on autonomy of higher education, but the higher education is skilled governed by bureaucratic, conservative, hierarchical, directing and dictating model. There is a need to realize Human Relations model. We need to revive our values and ethos. Education must be with the service motive than with mere profit motive. Higher education demands peaceful, harmonious environment. 


\section{References}

Value Education: Meaning, Objectives and Needs | India

Article shared by : Piyasa M

Higher Education in India: Challenges and Opportunities

Sheikh, Younis Ahmad, Journal of Education and Practice, v8 n1 p39-42 2017

Wwwmlaahl.edu.in>valueeducation

$\underline{\text { www.yourarticlelibrary.com>education>value.education }}$

David Starr Jordan-wikiquote Eric.ed.govIndia, International Bureau of education UNESCO, Indian Higher Education SAGE Publication

British Council, Understanding India- The Future of Higher Education and Opportunities for International Cooperation, 2014.

Agarwal, Pawan (2006) Higher Education in India: The Need for Change (ICIER Working Paper No. 180). New Delhi: Indian Council for Research on International Economic Relations, (http://www.icrier.org/publication/working_papers_180.html)

Singh, JD. (2011). Higher Education in India - Issues, Challenges and Suggestions. 